\title{
Moda tem tudo a ver com Idade: Definição de um Perfil de Novas Consumidoras da Terceira Idade
}

Fashion has all to do with age: Defining a profile for new consumers at the third age

DOMINGUES, Carolina Ângelo Jerônimo; Mestre; IF Sudeste de Minas Gerais

carolina.domingues@ifsudestemg.edu.br

DIEB, Helena de Azevedo; Mestre; Centro Universitário de João Pessoa

helena.dieb@unipe.br

BARBOSA, Uyara de Sousa Travassos; Mestre; Centro Universitário de João Pessoa

uyara.travassos@unipe.br

CUNHA, Rafaela Pontes; Graduada; Centro Universitário de João Pessoa

rafaelaapontes@gmail.com

QUEIROZ, Carina Vilar; Graduada; Centro Universitário de João Pessoa

ninaaqueirozz@gmail.com

MOUSINHO, Maura Carneiro Maldonado; Mestre; Centro Universitário de João Pessoa

maura.maldonado@unipe.br

\section{Resumo}

Este artigo corresponde a uma das etapas de desenvolvimento do projeto de pesquisa intitulado "Moda tem tudo a ver com idade: um estudo sobre o vestuário de mulheres acima de 60 anos", que teve como objetivo geral desenvolver uma coleção de moda para o público feminino da terceira idade, ocorrido no ano de 2014. A etapa aqui apresentada é o resultado e análise dos dados coletados por meio de entrevistas realizadas com mulheres de mais de sessenta anos de idade. $O$ objetivo foi conhecer as necessidades e desejos do público em relação ao que o mercado tem, ou não, a oferecê-lo. Utilizou-se como instrumento de coleta de dados um questionário semiestruturado a fim de conhecer as necessidades e expectativas dessa amostra em relação ao mercado da moda. São mulheres independentes economicamente e socialmente, mais satisfeitas em viver a terceira idade de modo ativo, porém que lamentam certas limitações físicas.

Palavras Chave: terceira idade; mercado; moda.

\section{Abstract}

This paper describes one of the phases of the project named "Fashion has all to do with age: a study about clothing of women over 60 years old", which has as general goal to develop a fashion collection for the women audience at the third age. The phase represented here is the result and data analysis from interviews with women over 60 years old. The goal was to know the needs and desires of this public related to what the market has to offer. The study had an exploratory and qualitative approach and used data collection mechanism a semi structured questionnaire in order 
to discover the needs and expectations from this sample related to the fashion design market. The content analysis obtained by the collection instrument was divided into five dimensions: demographic data, social activities, self-esteem, fashion market and third age against fashion. The results revealed an unusual profile. They were economically and socially independent women, satisfied in living the third age in an active way, however they regret physical limitations.

Keywords: third age; market; fashion. 


\section{Introdução}

Hoje em dia o ambiente doméstico não é o único espaço que o idoso circula. O interesse por universidades, academias de ginástica, cursos livres, turismo, lazer e outras tantas atividades, otimizam o cotidiano do idoso que se descobre tão produtivo e sociável, quanto aqueles de outras faixas etárias.

Este estudo parte do princípio de que este público tem desejos, características e motivações de compras diferentes por causa do seu estilo de vida, da idade e das dificuldades trazidas por ela. O processo de envelhecimento acarreta em uma série de mudanças fisiológicas, com características de corpo específicas da idade, tais como diminuição da massa muscular, força e função em muitos sistemas (GUSMÃO et al, 2015), menor mobilidade de braços e pernas, quadris mais largos, pele sensível que pede tecidos menos agressivos e sintéticos. 0 idoso tem necessidades específicas sobre o modo de uso do vestuário em relação à modelagem, corte e estrutura das roupas, conforto, comodidade, mobilidade, entre outros. E essas necessidades se alteram com o avançar dos anos, significativamente, já que uma pessoa de 80 anos possui necessidades diferenciadas da de 60 anos (SPIRDUSO, 2005).

Sendo assim, percebe-se que o vestuário deve atender as necessidades de diversos públicos em suas características demográficas (renda, classe social e idade) e psicográficas (estilo de vida, preferências e individualidade). No mercado encontram-se à disposição da sociedade lojas setorizadas por diversos segmentos, como adultos, adolescentes e crianças, que suprem as demandas masculinas e femininas, sem contar a variedade de estilo de vida e gosto. Observamos ainda que poucas lojas atendem públicos específicos, como o plus size, gestantes, atletas, evangélicos e certamente outros. Percebe-se, no entanto, que diante de toda essa variedade, há uma lacuna no mercado de moda: o público da terceira idade. Dessa forma, buscar compreender as necessidades e expectativas de senhoras idosas relacionadas aos produtos de vestuário, tornou-se o objetivo desse artigo.

Infelizmente, no Brasil, esse público, desvalorizado no mercado de trabalho, não é, também, amplamente convidado ao mercado consumidor. E quando é incluído, a sua condição parece estar sendo "mascarada", como se envelhecer não fosse um processo natural e que precisasse de estratégias direcionadas para além dos valores estéticos, como a adequabilidade às suas necessidades atuais, como o conforto e a praticidade.

Acreditamos que o processo de design pode responder aos vazios deixados pelo mercado da moda, conciliando, em novas propostas de vestimentas, uma modelagem que favoreça eventuais limites e dificuldades impostas pela idade a uma aparência capaz de atualizar tanto o "look" quanto a autoestima. Portanto, esse artigo objetiva apresentar a análise dos dados coletados em entrevista com o público alvo, que conduzirá nas tomadas de decisões quanto aos aspectos que devem ser valorizados no momento da criação de uma coleção específica a esse público.

\section{A Terceira Idade}

Às vezes um termo que designa uma determinada coisa, não consegue defini-la na sua totalidade. Um exemplo dessa situação são os termos designados para referirmo-nos aos idosos. Parece que desde os anos 1980, sob o ponto de vista de uma sociedade que quer adiar - nas aparências e comportamentos - o passar dos anos, os termos "velho" ou "idoso" incomoda. É 
como se o envelhecimento não fosse um processo natural, pertencente a cada pessoa vivente. $E$ sendo um assunto que, para muitos, costuma ser delicado, alguns termos foram utilizados para se referir ao idoso com brandura.

'Melhor Idade' é um desses termos. No entanto, diante da observação da experiência cotidiana, mesmo que houvesse o interesse em associar a velhice à falta de preocupação ou a uma maior disponibilidade de recursos financeiros e de tempo livre para atividades prazerosas como dançar, viajar, etc., alguém poderia, numa situação discordante desta tê-la sentido como irônica. Outro termo, mais aceito e como é mencionado em diversas publicações, é o 'Terceira idade'. Proposto inicialmente pelo gerontologista francês Huet, para abraçar o público que entra nos sessenta anos, passou a ser consenso em todas as organizações sociais e, também, nas ciências médicas.

É provável que a velhice traga consigo algum resquício de tristeza, um conceito de fragilidade, de fragmentação e de subtração que flutua sobre as estruturas subjetivas e concretas construídas por toda uma vida. Mas, é fato que nada é absoluto, pois nem a juventude é vivida na garantia plena de saúde e disponibilidade de tempo e dinheiro para aproveitá-la, assim como não são restritos aos idosos os movimentos do corpo, da mente, dos prazeres e dos afetos. Dessa forma (não tão adequada como analisa o campo da psicologia), este termo não unifica qualitativamente a velhice. É neutro, pois se refere apenas à idade cronológica. Assim, pode acolher as diferentes situações que se inserem nessa faixa etária.

Há poucas décadas, o idoso era compreendido como uma pessoa improdutiva, sem autonomia, sem desafios a vencer, sem desejos próprios, com necessidade de se preservar e descansar. Esse perfil vem se renovando, em resposta ou em paralelo aos incentivos para uma movimentação física e intelectual dos mesmos. E o que se percebe é o usufruto de uma maior qualidade de vida de pessoas, muitas vezes bem acima dos 60 anos - idade de entrada no que se convencionou chamar de terceira idade - que ainda trabalham, dirigem, praticam atividades físicas, estão voltando às salas de aula, fazem intercâmbios culturais e são economicamente ativas e produtivas.

Observa-se, nesse momento atual, que um novo perfil - especialmente formado por mulheres dentro do grande grupo da terceira idade - desabrocha na sociedade e no mercado consumidor. Elas sinalizam viver a experiência do envelhecimento com a capacidade de equilibrar as prováveis variáveis negativas próprias da avançada idade a uma forma positiva de encarar o envelhecimento, da qual fazem parte as atividades que as mantém conectadas com a vida social e cultural.

O panorama mudou. Podemos perceber a população descrita acima, como um público-alvo importante não só para o mercado que o está descobrindo como consumidor em diversos setores, mas também como objeto de estudos que façam interface entre moda e design.

Alguns estudos já foram feitos neste sentido, Menegucci e Santos Filho (2010), por exemplo, apresentam um levantamento dos estudos ergonômicos já desenvolvidos, apresentando a importância do estudo da ergonomia e da usabilidade para desenvolvimento do vestuário para o idoso. Também relatam a existência de alguns estudos sobre tecidos que apresentam funções específicas, que visam facilitar a utilização, os chamados Têxteis Técnicos ou Tecidos Tecnológicos. Os autores afirmam que apesar de não serem pesquisas voltadas para o público da terceira idade, podem ser levadas em consideração quando se desenvolve algo para este público. 
Outra pesquisa semelhante é a de Moura et al. (2013) que envolveu a criação e desenvolvimento de vestuário sleepwear para as idosas do Recanto dos Velhinhos de Cianorte-PR. Este estudo percebeu que não apenas as questões ergonômicas são importantes para este público. Além de conforto eles esperam beleza, jovialidade e vitalidade. Mesmo que alguns aviamentos como botões e zíperes dificultem o gesto de vestir, eles não descartam o seu uso porque também querem roupas bonitas e elegantes, inclusive escolhendo as roupas por cores mais vibrantes e com mais acessórios.

Também pode-se citar o trabalho de Ballstaedt (2007) que identificou o comportamento e estilo de vida da população idosa brasileira e seu poder de consumo. A pesquisa revelou um crescimento desta população específica e o aparecimento de um novo nicho de mercado, principalmente no mercado de moda. E conclui que o profissional de moda tem a responsabilidade de detectar as necessidades destes clientes a fim de atendê-los de forma satisfatória e diferenciada.

Dessa forma, este artigo refere-se ao estudo do comportamento de consumo de vestuário de idosos, principalmente o feminino, a quem essa pesquisa foi direcionada, partindo do princípio de que ele tem desejos e motivações de compras diferentes por causa do seu estilo de vida, anos de idade e das dificuldades trazidas por eles.

As pessoas com idade mais avançada geralmente apresentam algumas características corporais específicas que variam em função das diferentes idades: menor mobilidade de braços e pernas, quadris mais largos, o que vai requerer uma modelagem que promova conforto e mobilidade extras. A pele também pode se apresentar mais sensível ao toque de alguns tecidos, as vezes tão desconfortáveis por serem sintéticos.

\section{Metodologia}

Esta pesquisa possui uma abordagem qualitativa de caráter exploratório e o seu caminho metodológico seguiu alguns métodos para a realização de cada etapa. Antes da investigação de campo propriamente dita, no intuito de nos dar suporte na análise do conteúdo proveniente da entrevista apoiada a um formulário de pesquisa semiestruturado, a mesma seguiu algumas etapas importantes. A primeira etapa se deu a partir de uma revisão de literatura, para a investigação do estado da arte, analisando como o público da terceira idade está sendo definido nos tempos atuais, como tem sido desenvolvido o vestuário para este público, tanto do ponto de vista estético como ergonômico das peças. Sendo assim, foram utilizados como referências: livros, artigos, filmes e documentários. Esta etapa foi de extrema importância para entender o público que foi investigado por meio de uma pesquisa de campo.

A segunda etapa abrangeu a coleta de dados do público-alvo, que utilizou como técnica a entrevista apoiada a um formulário de pesquisa estruturado no intuito de conhecer em profundidade a amostra em questão. Oliveira et al (2012) define entrevista em profundidade como uma entrevista que possui uma maior flexibilidade, pois permite que o entrevistado construa seu pensamento sobre o questionamento mais livremente, sem precisar de respostas diretas ou mais rigorosas. Reiteramos ainda, que as entrevistas foram realizadas seguindo todas as recomendações da Resolução 466/12 do Conselho Nacional de Saúde, tendo sido o projeto aprovado pelo Comitê de Ética em Pesquisa (CEP).

A amostra desta pesquisa foi composta por 20 pessoas do sexo feminino e com idade 
acima de 60 anos. Optou-se por escolher mulheres, pois costumeiramente consomem mais e são mais vaidosas, além de contribuírem com informações mais ricas neste primeiro momento. Também contou para a escolha do público feminino ser ele a maior parcela da população. A pesquisa do IBGE (2002), por exemplo, diz que 62\% dos idosos são mulheres. Acima de tudo, foram selecionadas mulheres que apresentassem um comportamento independente e vida ativa para os padrões da terceira idade. Essas mulheres foram indicadas e selecionadas pelas pesquisadoras, por terem vidas autônomas e desprendidas de costumes antigos.

O instrumento de coleta de dados foi desenvolvido para coletar os dados desta amostra, no que tange às atividades de seu cotidiano como prática de exercícios físicos, locais que frequentam e o meio que utilizam para se locomover, bem como aborda o mercado de moda para terceira idade, gostos e preferências deste público. Os dados obtidos por esta pesquisa de campo foram submetidos a uma análise de conteúdo, de acordo com o que propõe Bardin (2009) e seus resultados serão apresentados e discutidos por este artigo. A autora define esse método como a verificação ou descoberta do que está por trás de cada conteúdo apresentado nos dados, correspondendo ao desvendamento dos significados de cada discurso, ou seja, de cada fala coletada. Moraes (1999) define a análise de conteúdo como descrições sistemáticas, que ajudam a interpretar as mensagens, compreendendo seus significados além de uma leitura comum dos dados.

Com essa análise é possível intuir ou deduzir comportamentos dos entrevistados. 0 pesquisador observa os dados e o comportamento do entrevistado e conclui o real significado da mensagem, revelando conexões existentes entre os vários discursos. 0 procedimento tem como objetivo observar todos os elementos presentes no discurso, e enxergar além do que foi exposto (PINTO, 2002).

O processo da análise foi iniciado com a categorização de conteúdo, que, para Moraes (1999), consiste em agrupar os dados semelhantes como uma parte comum, estabelecendo critérios semânticos ou por temáticas. Nessa etapa, os dados foram separados em cinco dimensões de análises. Sendo em seguida realizada a etapa de descrição, podendo fazer uso de tabelas e quadros para a organização dos dados e extração das informações, para em seguida ser produzido o texto de análise, uma síntese e interpretação de cada dado analisado do público consumidor.

As categorias definidas para esta pesquisa, dividem seus resultados em cinco dimensões: dados demográficos, atividades sociais/cotidiano, autoestima, mercado de moda e terceira idade $x$ moda. Essas dimensões foram definidas a partir dos conteúdos abordados no questionário semiestruturado utilizado para a pesquisa, buscando aproximar conteúdos que se complementam e que gerariam respostas próximas ou mesmo repetidas entre as entrevistadas. Esses dados serviram de base para o desenvolvimento de uma coleção de vestuário para o público-alvo em questão, se baseando em todos os seus anseios e vontades.

\section{Resultados e Discussão}

A análise das entrevistas resultou na compreensão do universo da mulher da terceira idade e sua relação com o mercado da moda. A análise está apresentada a seguir, tendo sido separada em tópicos para facilitar a compreensão. 


\subsection{Dados Demográficos}

Esta dimensão se delineia no Quadro 1 apresentado a seguir. Nele estão os dados que constroem o perfil das entrevistadas, que individualmente receberam um código, modo pelo qual elas serão identificadas ao longo do texto.

Quadro 1 - Dados demográficos das entrevistadas.

\begin{tabular}{|c|c|c|c|c|c|c|}
\hline Entrevistada & Idade & Escolaridade & Profissão & Est. Civil & Renda & Moradia \\
\hline 1 & $71-80$ & Sup. Completo & Aposentada & Viúva & 3-6 salários & Mora sozinha \\
\hline 2 & $>80$ & Sup. Completo & Dona de casa & Divorciada & $>8$ salários & Mora sozinha \\
\hline 3 & $60-70$ & Sup. Completo & Aposentada & Casada & 3-6 salários & 3 pessoas \\
\hline 4 & $60-70$ & Sup. Completo & Aposentada & Viúva & $>8$ salários & 1 pessoa \\
\hline 5 & $60-70$ & Ens. Fundamental & Aposentada & Solteira & 1-3 salários & 2 pessoas \\
\hline 6 & $71-80$ & Ens. Fundamental & Aposentada & Viúva & 1-3 salários & 2 pessoas \\
\hline 7 & $>80$ & Sup. Incompleto & Aposentada & Viúva & $>8$ salários & Mora sozinha \\
\hline 8 & $60-70$ & Sup. Incompleto & Aposentada & Divorciada & 1-3 salários & 2 pessoas \\
\hline 9 & $>80$ & Ens. Médio & Aposentada & Casada & 1-3 salários & 1 pessoa \\
\hline 10 & $60-70$ & Ens. Médio & Empresária & Casada & $\begin{array}{l}\text { Não } \\
\text { informado }\end{array}$ & 3 pessoas \\
\hline 11 & $60-70$ & Pós-graduação & Professora & Casada & 6-8 salários & 1 pessoa \\
\hline 12 & $>80$ & Ens. Fundamental & Não trabalha & Viúva & 1-3 salários & 2 pessoas \\
\hline 13 & $>80$ & Sup. Incompleto & Aposentada & Viúva & > 8 salários & Mora sozinha \\
\hline 14 & $71-80$ & Sup. Completo & Aposentada & Viúva & > 8 salários & Mora sozinha \\
\hline 15 & $71-80$ & Pós-graduação & Aposentada & Viúva & > 8 salários & Mora sozinha \\
\hline 16 & $71-80$ & Ens. Médio & Aposentada & Viúva & 3-6 salários & 4 pessoas \\
\hline 17 & $71-80$ & Sup. Completo & Aposentada & Viúva & $>8$ salários & Mora sozinha \\
\hline 18 & $71-80$ & Pós-graduação & $\begin{array}{l}\text { Atriz/ } \\
\text { educadora }\end{array}$ & Divorciada & 3-6 salários & Mora sozinha \\
\hline 19 & $60-70$ & Sup. Completo & Aposentada & Solteira & 1-3 salários & Mora sozinha \\
\hline 20 & $>80$ & Ens. Fundamental & Aposentada & Viúva & 3-6 salários & 2 pessoas \\
\hline
\end{tabular}

Fonte: desenvolvido pelos autores

Ficou decidido, que a amostra a ser entrevistada deveria ser do sexo feminino e ter mais de 60 anos, conforme corresponde ao termo terceira idade, segundo o Estatuto do Idoso, no artigo 1 
da Lei $n^{\circ} 10.741$ (BRASIL, 2003).

O Quadro 1 indica o perfil dessa amostra, no qual 35\% é composta por mulheres entre 6070 anos, 35\% por mulheres entre $71-80$ e 30\% por mulheres acima de 80 anos. Quanto ao grau de escolaridade, $55 \%$ têm curso superior completo e as demais se distribuem entre ensino fundamental, médio e superior incompleto.

A renda média de $30 \%$ das entrevistadas é de 8 salários mínimos. Apenas quatro das entrevistadas são casadas, as demais são viúvas ou divorciadas. Esse estado civil representa para elas liberdade, independência em sua vida e suas ações, desprendimento de rotinas e obrigações, entre outros aspectos que representam a liberdade de uma forma geral.

Há ainda aquelas que veem na viuvez ou na separação um motivo de solidão, porém, ao mesmo tempo sentem-se livres de não ter que cumprir com certas obrigações metodicamente, como almoçar no mesmo horário todos os dias, cuidar da casa, do esposo e dos filhos. Fatos que requerem da mulher além de disposição, cumprimento de horários. Algumas afirmaram sentiremse muito livres de poder dormir e acordar na hora que bem entendem, almoçar quando quiser e se quiser. Não ter que cumprir com obrigações do dia a dia as fazem sentirem-se livres e totalmente independentes. Pode-se verificar esse comportamento por meio do depoimento abaixo:

Eu amava muito meu marido, senti falta, mas depois que ele faleceu eu fiquei livre em não ter que cumprir com as minhas obrigações, faço o que quero quando quero (Entrevistada 14).

Quase todas as entrevistadas dizem que investem tanto no setor da moda quanto no de cosméticos, como também viajam sempre que podem. Algumas bancam a viagem de familiares próximos para acompanhá-las, vão a barzinhos, divertem-se com a família e grupo de amigos; muitas ajudam os filhos e familiares.

O fato de serem independentes financeiramente corrobora com a realidade de muitas morarem sozinhas. Elas veem neste fato a independência de poder fazer e até mesmo comprar o que bem entender, assim elas não necessitam da boa vontade de seus familiares para sua locomoção e suprimento de seus desejos, conforto e bem-estar. Esse fato é complementado quando analisamos as pesquisas sobre os lares brasileiros, a exemplo do IBGE (2002), que diz que dos lares onde os idosos são os responsáveis diretos pelas despesas, $18 \%$ deles são domicílios unipessoais, ou seja, com apenas um morador. Quando esses dados são analisados levando em consideração apenas a população feminina, o estudo aponta que cerca de $67 \%$ das idosas moram sozinhas.

\subsection{Atividades Sociais/Cotidiano}

A segunda dimensão procurou traçar o perfil das participantes com base na compreensão das atividades sociais que as mesmas costumam realizar em seu cotidiano. Ainda assim, comparou-se o novo modelo da terceira idade com o estereótipo que a sociedade designou a esse público.

Nesse sentido, os dados coletados se tornaram importantes para o desenvolvimento desta pesquisa, pois a partir deles pode-se entender, diferenciar o estilo de vida da mulher que se encontra na terceira idade em pleno século XXI e justificar a nova realidade que este público está inserido. É notório que uma grande parcela da terceira idade atual está integrada a uma rotina 
com novos costumes e atividades. Sendo assim, essa dimensão se faz necessária por buscar compreender, a partir do ponto de vista de cada entrevistada, essa mudança comportamental que influencia diretamente nas interações sociais.

A percepção que se tinha das mulheres da terceira idade, é que possuíam uma vida simples, eram recatadas, submissas aos maridos, que não possuíam vida social ativa e nem se importavam com sua aparência e com a moda. Habitualmente tinham como propósito atender às necessidades da sua família e sua figura ficava em segundo plano. Com relação às suas vestimentas possuíam características bem particulares, sendo elas na maioria das vezes parecidas com a dos membros mais velhos de sua família e que por muitas vezes eram herdadas, como exemplo as das suas mães.

Porém, com base na coleta de dados desta pesquisa, a mulher da terceira idade é ativa, independente, vaidosa, descomprometida, divertida, confiante e dona de si. O grupo entrevistado é descontraído e composto por mulheres autônomas, desprendidas, desobrigadas, despojadas, desimpedidas, espontâneas e desregradas. Evidenciou-se ainda que os hábitos mudaram e hoje, a maior parte delas moram sozinhas, viajam, praticam atividades físicas, namoram, saem com grupos de amigos, vivem desprendidas de costumes que antes eram seguidos. Dentro deste contexto, voltamos a atenção para a declaração da entrevistada 18:

Das 6:00h da manhã às 23:00h da noite eu estou no ar. São 56 anos, foi, foi um bichinho entrou no sangue, nunca parei, nem grávida, nem de resguardo e fazendo teatro... como eu tenho grupo de teatro aí já encontro com os amigos e de lá a gente sai ou marca mesmo.

Este grupo mais ativo, que identificamos como a maior parcela das entrevistadas, demonstra ter uma vida agitada, que inclui em sua rotina a prática de exercícios físicos, ou por indicação médica ou por apreciar a atividade. Ainda assim, evidenciam ter uma maior interação social - elas saem mais, têm encontros mais assíduos com família e amigos.

Visto que este grupo apresenta uma maior disposição para qualquer tipo de atividade, tanto física quanto social, nota-se que essas mulheres demonstram estar mais satisfeitas em viver a terceira idade, porém lamentam ter tantas limitações, principalmente físicas.

\footnotetext{
Desde muito nova gosto de me exercitar... quando a idade chega temos mais necessidade de cuidar do corpo... não adianta viver tanto e não ter saúde para aproveitar... eu caminho, faço academia... me sinto bem, mesmo tendo um monte de limitações... estar vivendo até hoje é muito bom, mas sinto muita falta da energia que tinha anos atrás... mas mesmo assim aproveito todo tempo que tenho (Entrevistada 17).
}

Sendo assim, pode-se associar que o fato destas mulheres saírem de casa para praticarem exercícios físicos gera, consequentemente, um estímulo para terem uma vida social mais ativa. Logo, as mesmas possuem grupos de amigos, saem mais de casa e viajam com maior frequência, como evidencia-se na fala abaixo.

Estava sentindo falta de fazer algo diferente... é muito incomum estudar inglês na minha idade... me sinto mais viva... Faço inglês duas vezes na semana. Treino com meus netos, eles acham o máximo... é muito bom fazer coisas diferentes nessa altura do campeonato (Entrevistada 15).

Dadas às exceções, percebeu-se também que existe, além do grupo das mulheres ativas, uma parcela minoritária de participantes que são mais sedentárias, que preferem ter uma vida mais caseira e sem muitas obrigações. Ainda assim, não participam de grupos sociais e em grande 
parte só possuem relacionamento com a sua família.

Além de não possuírem tanta disposição física e social, essas idosas apresentam um ritmo de vida mais lento. O sedentarismo muitas vezes está relacionado às limitações físicas ou de saúde, resultando em uma vida mais estática. Este fato é decorrente, de certa forma, de um comodismo, pois, depois de longos anos repletos de regras e servindo à família, a mulher interpreta a morte do marido como uma forma de liberdade, excluindo assim todas as possibilidades de compromisso com qualquer tipo de atividade, seja ela física, social ou doméstica como está explicitado abaixo:

Eu não sou como umas amigas minha que acordam cedo para caminhar e têm seus horários certinhos, eu me acordo tarde e a hora que eu achar bom, faço o que quero. Ultimamente estou indo dormir cada vez mais tarde assistindo (Entrevistada 07).

Percebeu-se ainda que, sendo ou não ativas, as mulheres da terceira idade associam essa fase a uma liberdade nunca antes experimentada. Logo, as idosas de hoje são mais independentes e exercem um maior papel social. Esta independência pode ser percebida em aspectos como decidir morar só, bem como está associada com a possibilidade de locomoção urbana.

No que tange à locomoção urbana, percebe-se, segundo alguns relatos, que a maioria das participantes ao atingir a terceira idade decidiu não dirigir mais seus veículos. As justificativas são muitas, porém sofrem variações desde o medo até o tédio de exercer a atividade ou das condições atuais do trânsito. E como alternativa de locomoção, muitas possuem motoristas particulares, ou utilizam táxis e transportes público ou desfrutam da ajuda dos seus filhos.

Passei minha vida inteira dirigindo... gosto de não precisar dirigir mais... faço aquilo que tenho vontade... dirigir não é mais legal. Antes eu até gostava, era uma coisa necessária, hoje consigo viver sem dirigir (Entrevistada 14).

Com base em todas as informações coletadas em relação a suas atividades sociais e ao seu cotidiano, conseguimos perceber a notória diferença da terceira idade do século XXI com a de anos atrás. A idosa de hoje não se considera uma idosa. Ou seja, elas ainda são mulheres dispostas, fazendo ou não atividades físicas, conseguem aceitar e desfrutar tranquilamente a fase que estão vivendo. São muito diferentes do que suas mães foram com essa idade, mas demonstram que essas diferenças são mais positivas do que negativas. Sendo assim, torna-se perceptível que muitas dessas senhoras estão deixando para trás o estereótipo que a sociedade formou a respeito das mesmas e formando uma nova imagem acerca do que é viver e aproveitar a terceira idade.

Deste modo, pode-se dizer que o perfil do grupo participante, além de independentes, são mulheres alegres, divertidas, dispostas e autônomas. O que contradiz com a imagem geral que se tem das mulheres da terceira idade, como já citado. No entanto, diante deste novo contexto, percebe-se que este público se porta à sociedade de maneira mais autêntica e de forma mais prazerosa, elas já não são mais impostas pelo que a sociedade acha que deve ser, e sim se comportam da maneira que bem entendem.

\subsection{Autoestima}

A dimensão autoestima teve como objetivo principal compreender e analisar a forma como as mulheres da terceira idade lidam com sua autoestima. Sendo assim, levamos as mesmas a um momento de reflexão quanto ao que acham de si próprias. As perguntas foram desenvolvidas com base em pesquisas e estudos acerca do comportamento da mulher que está na terceira idade, e a 
forma como as quais costumam se cuidar.

Tratando-se de um estudo sobre consumo de moda, a vaidade está estreitamente ligada à autoestima, logo, ambas se tornam elementos fundamentais para traçar um perfil de consumo das participantes. Segundo o pesquisador Maia (2005) entende-se que autoestima é a:

[...] opinião acerca de si, somada ao valor ou sentimento da própria imagem, adicionado a todos os demais comportamentos e pensamentos que demonstrem a confiança, segurança e valor que o indivíduo dá a si, nas relações e interações com outras pessoas e com o mundo.

A percepção da autoestima perpassa pelo entendimento da vaidade, de anseios por maiores cuidados e da preocupação com a aparência. As respostas em sua maioria foram bastante homogêneas, dessa forma conseguimos traçar um perfil singular para as entrevistadas que se descrevem como mulheres simples, que não se acham muito vaidosas, mas que demonstram cuidados com a aparência. Abaixo as entrevistadas relatam a sua relação com a vaidade.

Não, não diria vaidosa, mas não sou vaidosa eu sou muito metódica, não saio de casa sem me pintar aconteça o que acontecer, sem tomar meu café e me pintar, eu acordo meia hora antes se for o caso, mas é isso, eu tenho e não quero quebrar (Entrevistada 18).

Eu, eu gosto de me ajeitar sabe, eu gosto, não sou muito vaidosa, mas gosto de tratar o cabelo, ter uma boa aparência, vestir bem (Entrevistada 03).

Com base em todos os dados coletados, chegamos à conclusão que a maioria das entrevistadas são vaidosas, porém muitas delas têm dificuldades ou vergonha em assumir isso. Este fato pode ser reflexo de um perfil previamente determinado para as mulheres dessa idade. Entretanto, conseguimos compreender ao longo do desenvolvimento dessa pesquisa, que a terceira idade não está relacionada ao desleixo com a aparência, pelo contrário, as idosas do século XXI gostam cada vez mais de se cuidar e de se preocupar com a sua estética.

\subsection{Mercado e Moda}

A dimensão analisada a seguir relacionou o público em questão com o mercado da moda. $O$ intuito das indagações realizadas é entender se estas mulheres conseguem obter com facilidade produtos de moda adequados às suas necessidades no atual mercado, visto que, existem poucas lojas/marcas especializadas nesse crescente nicho de mercado. Essa é uma faixa etária em constante crescimento, Novais (2005) ressalta que entre 1950 e 2025, esta população no Brasil crescerá 16 vezes contra 5 vezes da população total.

Frente aos dados obtidos, percebemos que, ao mesmo tempo que as participantes são vaidosas e gostam de se vestir bem, existe ainda uma grande rejeição ao envelhecimento do corpo, sendo visto como um grande tabu.

Saber que seu corpo vai mudar, que os cabelos vão embranquecer, as rugas vão aparecer, que as formas do seu corpo não serão mais iguais ao da sua juventude, assusta, principalmente para as mulheres, que são mais vaidosas que os homens. Desta forma, este é mais um fator que as fazem optar por peças mais folgadas e fechadas, como explicita bem as falas abaixo:

Quando você chegar a essa idade vai entender que nada cai muito direito no corpo. Meu corpo era lindo, mas agora é muito difícil me vestir. Estou acima do peso, já levei algumas roupas para costureira. Vou emagrecer e achar umas roupas mais bonitas (Entrevistada 13).

Já usei tomara que caia, mas hoje meus braços não tão mais bonitos. Então, eu gosto de 
colocar as mangas $3 / 4$ (Entrevistada 02).

Em contrapartida, algumas mulheres dizem ter aceitado as mudanças que vem junto à terceira idade com tranquilidade. Comentam sobre o privilégio de se chegar a esse momento da vida, deixando claro que se deve ter orgulho como relata a Entrevistada 20: "A idade não é pra inibição, idade é um privilégio".

Também pode-se citar o conforto como um ponto primordial para a escolha das peças que serão consumidas. Para algumas das participantes é mais importante, na aquisição de roupas, o fato das mesmas serem confortáveis do que elas estarem ou não seguindo as tendências de moda. A moda para a consumidora da terceira idade, segundo Menegucci e Santos (2010), é deficiente, pois existem poucos estudos que fornecem dados para a construção de um vestuário ergonômico, qual deveria possuir uma modelagem adequada às novas formas do corpo, inserção de elementos de interação para facilitar a usabilidade, bem como o uso de matérias primas que atendam às necessidades físicas do idoso.

É possível detectar que somente na década de 1960 surgiram as tendências de roupas direcionadas para públicos específicos, como exemplo o público jovem e as pessoas de meiaidade. Gonçalves (2002) ainda afirma que esta segmentação era obedecida pelos públicos e quando não, eram discriminados.

Ballstaedt (2007) ainda destaca que atualmente não existe mais preconceitos com a idade, apontando que o que define o que pode ou não pode ser ideal para cada faixa etária é o tipo de corpo e as atividades sociais e profissionais. A falta das regras é fato. Entretanto se verifica na fala de algumas das entrevistadas, certas limitações subjetivas da idade.

Tem gente de 60 anos que parece uma perua (Entrevistada 19).

Para chinelinho tem sempre um pezinho cansado. Para cada idade a sempre um estilo adequado (Entrevistada 19).

Precisam se vestir de uma maneira saudável, sem se tornar ridícula. Não muito curto, não muito decotado, que seja compatível com sua idade (Entrevistada 17).

Às vezes gostaríamos de usar coisas mais incrementadas, mas ai você acha que pode ficar ridícula (Entrevistada 17).

Não acho que roupa tem idade, posso usar o que quiser... tenho muita noção das coisas que uso, mas tem um monte da minha idade e outras bem mais velhas que não sabem o que vestir e ficam vulgares demais (Entrevistada 14).

Equilibrar todos esses aspectos em questão, não é tarefa fácil. Há um público específico e um mercado que propõe uma jovialidade que nem sempre se adequa a alguns grupos de pessoas, como o caso da terceira idade. Estar na moda ou não parece não ser o ponto crítico. Mas observase que essas consumidoras não aceitam os extremos. Sugerem a existência de um meio termo entre as tendências de moda que não as contemplam na totalidade e as formas recatadas de vestir.

Para Ballstaedt (2007, p.12) "fazer moda para pessoas idosas não significa renega-las a um padrão estético preconceituoso (...)". A autora afirma que pessoas de qualquer idade têm gostos distintos, em relação ao feitio, estampas e cores. Umas são clássicas, outras ousadas. 0 envelhecimento não anula a personalidade e isso deve ser respeitado.

\subsection{Terceira Idade $\mathbf{x}$ Moda}


Por fim, na quinta e última dimensão, buscou-se compreender a relação deste público com o conceito de Moda, pois o mesmo não deve abranger apenas as convenções de beleza, bem como não deve se restringir à idade. De uma maneira geral, os dados coletados relacionam a definição de Moda com a forma com a qual as pessoas se vestem, estas diretamente ligadas à beleza e ao bem-estar, como é visto logo abaixo.

Moda é o que está se usando naquela época (Entrevistada 15).

A moda da terceira idade de hoje não é como antigamente, igual ao tempo da minha mãe, é mais moderna (Entrevistada 15).

O tempo da cadeira de balanço e do tricô já passou (Entrevistada 16).

Porque o meu gosto está inserido nessa moda e a moda inserida no meu gosto (Entrevistada 17).

Assim sendo, percebe-se que o conceito de Moda para este público está intrinsicamente ligado às tendências do mercado. Mercado este, que deve levar em consideração as limitações físicas da idade da usuária, bem como os gostos e preferências de modo a atender todas as necessidades e anseios destas idosas.

Segundo Almeida (2012), precisa-se ter cuidado na escolha das cores e estampas utilizadas nas roupas dos idosos, pois as mesmas devem ser discretas e nunca chamativas. Em contraposição ao estereótipo criado deste público, buscou-se, por meio de questionamentos, identificar as suas preferências e ratificar a veracidade da descrição feita pelo autor acima.

No entanto, os dados divergiram com os de Almeida (2012). Identificou-se um nicho de mercado mais moderno, que gosta e consome peças de roupas com cores fortes e vibrantes, bem como estampas grandes. Este público deixou de se vestir de forma característica, como antes vista nos idosos, e passou a expressar a sua identidade e gostos por meio, também, das suas vestes.

Gosto de chegar chegando em todos os lugares. Adoro usar tecido estampado e cores bem alegres... Sou muito bonita, todo mundo tem que me notar mesmo (Entrevistada 17).

Gosto muito de usar preto, de usar brilho, mas tudo dentro do limite (Entrevistada 01).

Lisas e estampadas. Agora, estampa eu gosto bem discreto. Gosto muito de estampa, mais lisa eu gosto mais (Entrevistada 01).

Sendo assim, percebe-se um grande interesse desta amostra em lojas de roupas especializadas no perfil da terceira idade, que atendam às suas necessidades físicas e seus anseios no que tange às tendências de moda.

Uma loja exclusiva para terceira idade seria uma ótima ideia, principalmente para "aquelas" que são exageradas se vestirem de acordo com a sua idade (Entrevistada 16).

Mas é logico que sim, claro. Gosto de dá preferência a quem me dá também (Entrevistada 19).

\section{Considerações Finais}

É consensual que para o desenvolvimento de uma coleção de moda deve-se considerar, além do planejamento de uma roupa adequada no que tange a ergonomia e vestibilidade, características que levem o público ao acesso a uma nova condição de vida. Esses benefícios, como já citado na apresentação do projeto, se relacionam a outras áreas que se envolvem, nos 
limites desse projeto, no processo de envelhecimento. Como por exemplo, a psicologia, a fisioterapia e o marketing. A psicologia tendo a roupa como elemento que pode ser capaz de elevar a autoestima das pessoas. A fisioterapia, que poderá contar com soluções de design que se adequem às questões corporais recorrentes ao público. E o marketing que poderá descobrir esse novo público, o que viria renovar suas leis e práticas para interpretá-lo e envolvê-lo.

Com base neste projeto, pretende-se ampliar os estudos acadêmicos para este público na área da moda, visto que se trata de um assunto pouco tratado e analisado desde o início de criação da profissão do designer de moda. Com isso, pode-se contribuir com a sociedade, servindo de base para futuras pesquisas, com públicos diferentes, e que também tenham certas limitações, tais como os deficientes físicos.

A escolha deste público deve-se ao fato de que a longevidade vem aumentando o número de idosos na população. Segundo dados do IBGE (2002), a população de idosos poderá ultrapassar os 30 milhões de pessoas até 2020. A maioria vive nas grandes cidades e mais da metade corresponde ao sexo feminino, público, a quem se dirige esta pesquisa, que se revela potente e promete ser ainda mais significativo do que hoje.

Sendo assim, com base no quantitativo das análises, foi percebido que o perfil da mulher da terceira idade não condiz com a forma como grande parte da sociedade a concebe. Com o passar do tempo os "hábitos" que vestiam ou caracterizavam as mulheres recatadas e solitárias das senhoras da terceira idade se modificaram. E os estereótipos não definem mais um certo grupo de senhorinhas de mais de 60 , aquelas que ainda têm muito a oferecer e principalmente usufruir.

Nessa pequena amostra entrevistada se registrou situações, identidades, necessidades e valores diferentes. A análise das respostas e opiniões revelou que são muitos os aspectos que delineiam as questões da terceira idade em relação à moda. Em síntese, giram em torno da adequação dos limites subjetivos e físicos a uma forma pessoal de vestir-se que dispensa marca e luxo, pois conforme as entrevistadas 01 e 17, ser chique e elegante dispensa a grife, mas se pretende livre de paradigmas e preconceitos, valorizando o conforto e elegância.

Contudo, contemplar este público tão específico com criações de moda irá requerer conhecimentos e pareceres de profissionais da saúde que possam colaborar com o design de moda para garantir uma relação eficaz com a roupa. Além do mais, poderá dispensar tendências massificadas da moda. O que não pode faltar é estilo, cor e a busca pelo bem-estar.

\section{Referências}

ALMEIDA, M. Vestindo-se bem em qualquer idade. Jornal Cruzeiro do Sul. 16 mar. 2012. Disponível em: < http://www.jornalcruzeiro.com.br/materia/372346/vestindo-se-bem-emqualquer-idade>. Acesso em: 07 out. 2015.

BARDIN, L. Análise de Conteúdo. Lisboa: Edições 70, 2009.

BALLSTAEDT, A. L. M. P. Comportamento e estilo de vida da população idosa e seu poder de consumo. In: Encuentro Latinoamericano de Diseño. Buenos Aires, 2007.

MOURA, C. B.; CAMPUS, I. N.; VIEIRA, J.; MENEGUCCI, F.; FAGANELO, L. R.; BARCELOS, S. M. B. D. O Idoso e o vestuário: considerações ergonômicas e elaboração de protocolos de pesquisa. Anais do $1^{\circ}$ Congresso Científico Têxtil e de Moda - CONTEXMOD. São Paulo, abril de 2013. 
BRASIL. Lei 10.741, de 01 de outubro de 2003. Dispõe sobre o Estatuto do Idoso e dá outras providências. Disponível em: < http://www.planalto.gov.br/ccivil_03/leis/2003/L10.741.htm>. Acesso em: 02 out. 2015.

GONÇALVES, X. Donna: abc da moda. Porto Alegre: Zero Hora Editora jornalística, 2002.

GUSMÃO, M. F. S.; DUARTE, S. F. P.; LAGO, L. S.; NASCIMENTO, C. P.; ALMEIDA, R. F. F. de; REIS, L. A. dos. Mensuração das pressões respiratórias máximas em idosos participantes de grupos de convivência. InterScientia, João Pessoa, Vol. 3, no 2, p. 133 - 141, 2015.

IBGE. Perfil dos idosos responsáveis pelos domicílios. 25 Julho 2002. Disponível em: < https://ww2.ibge.gov.br/home/presidencia/noticias/25072002pidoso.shtm>. Acesso em: dezembro de 2017.

MAIA, E. Mas o que é autoestima? Instituto de psicologia aplicada. 07 abr. 2005. Disponível em: <http://www.inpaonline.com.br/auto-estima/>. Acesso em: 02 out. 2015.

MENEGUCCI, F.; SANTOS FILHO, A. G. Proteção e conforto: a relação entre os tecidos e o design ergonômico do vestuário para idosos. 9o Congresso Brasileiro de Pesquisa e Desenvolvimento em Design. 2010.

MORAES, R. Análise de conteúdo. Revista Educação, Porto Alegre, v. 22, n. 37, p. 7-32, 1999.

NOVAIS, R. C. Baby Boomers na Terceira Idade, Uma Oportunidade de Mercado: Um Estudo da Indústria de Cosméticos Natura. In: XXVIII Congresso Brasileiro de Ciências da Comunicação, setembro 2005.

OLIVEIRA, V. M. de; MARTINS, M. de F.; VASCONCELOS, A. C. F. Entrevistas "em profundidade" na pesquisa qualitativa em administração: pistas teóricas e metodológicas. In: XV Simpósio de Administração da Produção, Logística e Operações Internacionais. Ago.2012.

PINTO, M. J. Comunicação e discurso. 2a edição. São Paulo: Hackers, 2002.

SPIRDUSO, W. W. Dimensões Físicas do Envelhecimento. São Paulo: Manole, 2005. 